\title{
Соцветие Silene jailensis N.I. Rubtzov (Caryophyllaceae)
}

\author{
АЛЕКСАНДР РОСТИСЛАВОВИЧ НИКИФОРОВ
}

НІкІфоров О. Р., 2011: Суцвіття Silene jailensis N.I. Rubtzov (Caryophyllaceae). Чорноморськ. бот. ж., Т. 7, № 2: 126-131.

\begin{abstract}
Вивчалася структура суцвіття реліктового ендеміка Гірського Криму Silene jailensis. Досліджено, що вихідне суцвіття рослин S. jailensis належить до сьомиквіткового діхазію.. У рослин in situ повністю домінують форми трьохквіткового цимоїда, що $\epsilon$ результатом дефіциту тепла для генеративного розвитку рослин.
\end{abstract}

Ключові слова: : Silene jailensis, Крим, релікт, сезонний ритм, суцвіття

Nikiforov A. R., 2011: Silene jailensis N.I. Rubtzov (Caryophyllaceae). Chornomors 'k. bot. $z$, Vol. 7, № 2: 126-131.

The inflorescence structure of relictual species Silene jailensis, endemic to the Crimean Montains was studied. Initially, S. jailensis has dichasial cyme with seven flowers.. The impoverished cymes with three flowers fully dominate in plants in situfor the reason of the lack of summer warmth for proper generative development of plant.

Keywords: Silene jailensis, Crimea, relict, seasonal development, inflorescence structure.

Никифоров А. Р., 2011: Соцветие Silene jailensis N.I. Rubtzov (Caryophyllaceae). Черноморск. бот. ж., Т. 7, № 2: 126-131.

\begin{abstract}
Изучалась структура соцветия реликтового эндемика Горного Крыма Silene jailensis. Выявлено, что соцветие растений $S$. jailensis относится к семицветковым дихазиям. Соцветие формируется цветками на главной оси и боковыми цветками на осях второго и третьего порядков ветвления. У растений in situ полностью доминируют формы трехцветкового цимоида, что является следствием дефицита тепла при генеративном развитии растения.
\end{abstract}

Ключові слова: Silene jailensis, Крым, реликт, сочветие

Популяции симподиального полукустарничка $S$. jailensis N. I. Rubtzov (Caryophyllaceae) локализованы на известняках альпийских стен Никитской яйлы в верховьях реки Авунда (1350-1430 м над ур. м.), Гурзуфского яйлинского массива (1430-1490 м н. у. м.) и на клифе горы Парагильмен (800-853 м над ур. м.) южного макросклона Главной гряды Крымских гор [ЕНА, ЕНА, 2001; НикиФОРОВ, 2004].

Возрастные спектры исследованных популяций свидетельствуют о «...катастрофически низком уровне семенного возобновления и преобладании процессов старения в популяциях S. jailensis» [ЕнА, ЕНА, 2001: 31]. Малочисленность популяций поясняют трансформацией рельефа яйлы в четвертичное время. «Очевидно, снижение абсолютной высоты Главной гряды, которое происходило сходным образом на многих ее участках, вызвало в прибровочных экотонах столь существенные изменения экологических условий, что они далеко опередили адаптационные возможности S. jailensis и поставили ее метапопуляцию на грань исчезновения» [ЕНА, ЕНА, 2001: 32].

Вид размножается только посредством семян: «...придаточные корни не образуются даже при засыпании побегов субстратом» [ЕНА, ЕНА, 2001: 29]. Таким

\footnotetext{
(C) О.Р. Нікіфоров

Чорноморськ.бот.ж, Т. 7, №2: 126-131.
} 
образом, численность популяций прямо зависит от семенного возобновления растений. Возобновление же растений в популяциях зависит от урожайности плодов и семян. Урожайность, в свою очередь, определяется условиями развития особей (с кульминацией в период цветения и плодоношения) и количественными параметрами соцветий (числом цветков).

Соцветие S. jailensis характеризуют как одно-двух или трехцветковое [РуБцОв, 1974; ЕНА, ЕНА, 2001; ФЕДОРОНчУк, 2006]. В действительности же при абсолютном преобладании одно и двухцветковых соцветий у растений изредка фиксируются побеги с соцветием из пяти цветков [НиКИФОРОВ, 2007]. Примечательно, что диночные цветки и малоцветковые соцветия (до трех цветков) образуют арктические или альпийские виды [КОНДОРСКАЯ, 1979].

Цель настоящей работы - охарактеризовать структурные особенности соцветия S. jailensis. Задача - выявить экологические условия, которые влияют на формирование у растений генеративных побегов и развитие соцветий.

\section{Методика исследования}

В соответствии с типологической концепцией синфлоресценции (по Троллю) соцветие представляет собой морфоструктуру из системы цветоносных осей, число и порядок взаиморасположения которых закреплен в генотипе вида [ФЕДОРОВ, АРТЮШЕНКО, 1979; КОНДОРСКАЯ, 1979, 1989; КУЗНЕЦОВА, 1985]. При определениИ тиПа соцветия S. jailensis учитывались способ ветвления генеративного побега, внешний облик соцветия, порядок зацветания осей. Генеративный этап развития растений фиксировался с момента формирования вегетативной сферы будущего генеративного побега и до его цветения. Соцветие изучалось от времени появления генеративных зачатков и до завершения генезиса этой структуры.

\section{Результаты исследования}

Зачатки генеративных органов $S$. jailensis закладываются после зимовки растений, после того как на границе прошлогоднего прироста каждой скелетной ветви формируется розетка листьев. При среднесуточной температуре воздуха около $+10^{\circ} \mathrm{C}$ и выше в пазухах листьев этой розетки раскрываются почки, которые дают боковые розеточные побеги.

Терминальная розеточная морфоструктура состоит из розетки на верхушке многолетнего побега и боковых побегов (от 1 до 6). При среднесуточной температуре воздуха около $+15^{\circ} \mathrm{C}$ и выше терминальный побег первым начинает рост и остается вегетативным, а в боковых розеточных побегах закладываются генеративные зачатки. Сразу после заложения генеративной сферы боковые побеги удлиняются, обгоняя по высоте нарастающий терминальный побег (рис. 1).

Зачаточный генеративный побег несет на центральной оси терминальный бутон с зачатками кроющих листьев и двух боковых осей с бутонами и прицветниками (рис. $1,2)$. Часто боковые оси остаются недоразвитыми и тогда генеративный побег $S$. jailensis дает одноцветковое соцветие из терминального цветка, завершающего главную ось (ось первого порядка синфлоресценции) (рис.1).

Развитие одной из боковых осей усложняет структуру соцветия до терминального цветка и цветка на боковой оси. Терминальный цветок главной оси соцветия всегда зацветает первым, а второй цветок завершает боковую ось второго порядка, берущую начало из пазухи кроющего листа (рис. 1, 2). Иногда наблюдаются соцветия без терминального цветка: одноцветковые, состоящие из одного из боковых цветков и двуцветковые - вильчатые соцветия из цветков на боковых побегах-осях. 


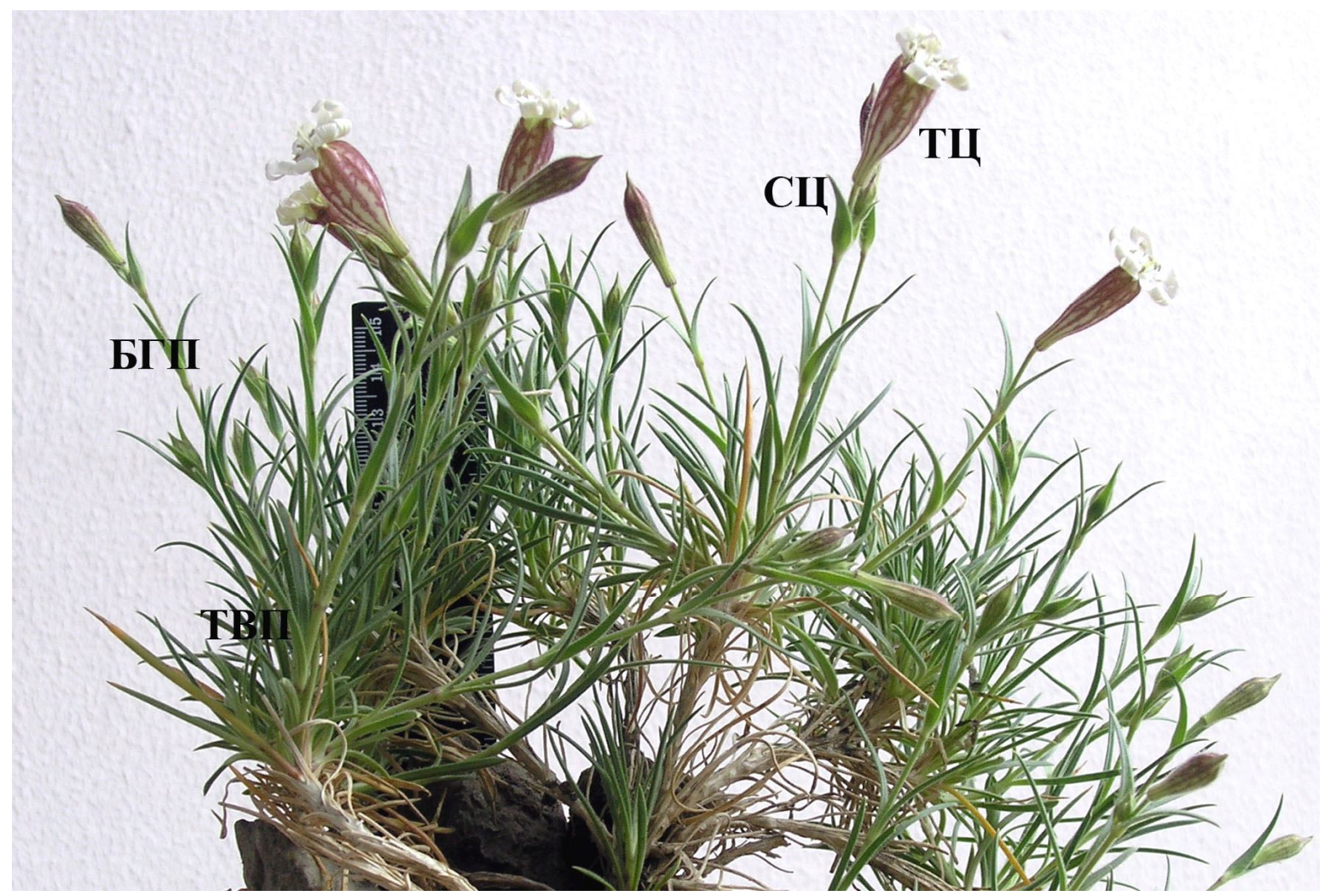

Рис. 1. Цветущий экземпляр Silene jailensis.

Условные обозначения:

ТВП - терминальный вегетативный побег; БГП - боковой генеративный побег; СЦ - соцветиедихазий; ТЦ - терминальный цветок центральной оси соцветия первого порядка ветвления.

Fig. 1. Plant of Silene jailensis with flowers.

ТВП - terminal vegetative shoot; БГП - lateral vegetative shoot; СЦ - dichasial cyme; ТЦ - terminal central flower of first branch

Варианты одно и двуцветковых соцветий образуются в результате подавления пазушного развития тех или иных осей. Исходной морфоструктурой для всех этих форм соцветий, соответствующих монохазию, служит цимоид типа дихазия-триады [КОНДОРСКАЯ, 1979, 1989]. Полное соцветие-триада состоит из главной оси (первого порядка), двух боковых осей с одиночными цветками (второго порядка) (рис. 2).

Соцветие типа триады у растений данного вида формируется довольно редко [НикифОРОВ, 2007]. Трехцветковый цимоид обычно реализуется в качестве однодвуцветковых соцветий. Тем не менее, в соцветиях часто наблюдаются недоразвитые оси (с бутонами или без бутонов) второго и даже третьего порядка.

Неполные формы указывают на иной, чем триада, исходный тип соцветия вида. Двуцветковое соцветие побега растения $S$. jailensis с осью третьего порядка формируется в случае формирования побегом единственной боковой оси второго порядка и развития при ней еще одной боковой оси (при отсутствии терминального цветка на главной оси и противоположной боковой оси). Трехцветковое соцветие образуется при наличии терминального цветка на центральной оси и бокового цветка на оси второго порядка, а позже - развития здесь боковой оси третьего порядка.

Четырехцветковые соцветия служат результатом ложной дихотомии (при двустороннем ветвлении боковых осей до третьего порядка в отсутствие терминального цветка на главной оси). Пятицветковые соцветия побегов включают цветок главной оси, а также по два цветка боковых осей второго порядка и третьего порядка ветвления (при редукции вторых цветков в каждой паре боковых ответвлений) (рис. 2). 


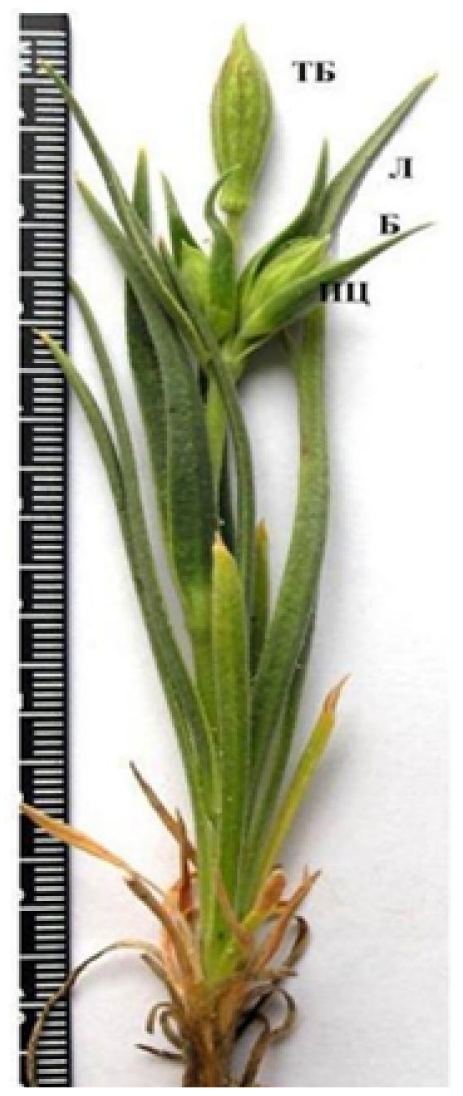

A

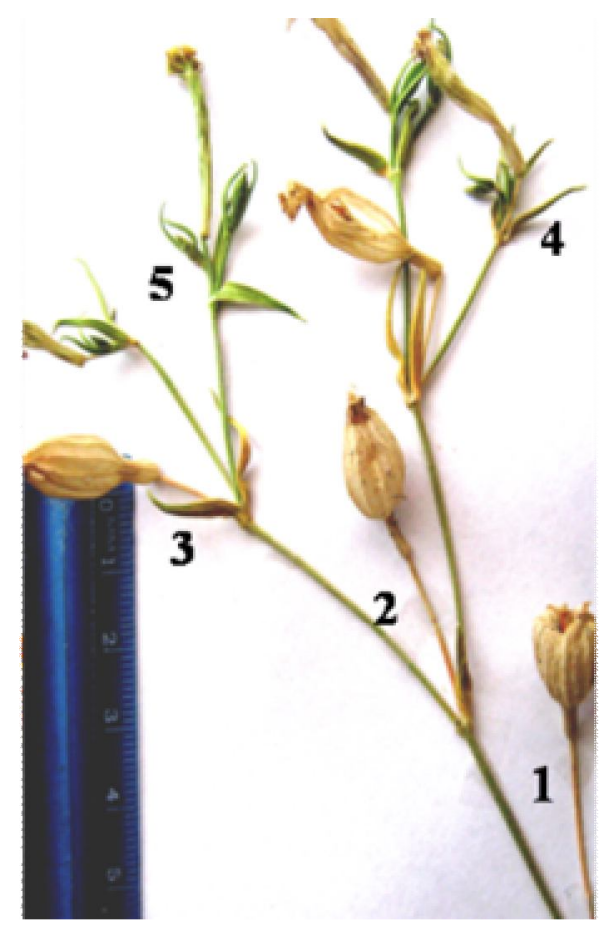

Б

Рис. 2. Соцветие $S$. jailensis.

а) генеративный побег в фазе бутонизации; б) Сформировавшееся соцветие.

Условные обозначения:

ТБ - терминальный бутон; Б - боковой бутон; Л - кроющий лист при терминальном цветке на оси первого порядка ветвления; ПЦ - прицветник при боковом бутоне на оси второго порядка ветвления; Б - брактея при зачаточном боковом бутоне третьего порядка ветвления.

Fig. 2. Inflorescence of S. jailensis.

a) generative shoot with flower buds; b) developed biparous cyme .

Symbols: ТБ - terminal flower bud; $\mathbf{5}$ - lateral flower bud; Л - bract of the first branch terminal flower; ПЦ - bract of the lateral flower bud of the second branch; 5 - bract of the lateral flower bud of the third branch.

Все перечисленные варианты соцветия служат формами уже не триады, а более сложного по структуре соцветия - двойного дихазия [ФЕДОРОВ, АРТЮШЕНКО, 1979; КОНДОРСКАЯ, 1979, 1989]. Такой дихазий потенциально состоит из семи цветков. Это терминальный цветок на главной оси соцветия и цветки на боковых супротивных осях еще двух порядков ветвления. Структуру соцветия последовательно составляют на первом этапе - главная ось и боковые оси из пазух прицветников (максимум три цветка), а на втором этапе развития - оси третьего порядка ветвления из пазух брактей (максимум четыре цветка). Синфлоресценция побегов S. jailensis идентифицируется (по Троллю) как фрондо-фрондулозно-брактеозный закрытый цимоид (монотирс) [ФЕДОРОВ, АРТЮШЕНКО, 1979; КОНДОРСКАЯ, 1979].

\section{Обсуждение}

У растений, произрастающих in situ, соцветие у основной массы побегов устойчиво обедняется. Боковые оси, формирующиеся в результате деятельности пазушных меристем соцветия, в природных условиях подавляются еще в период 
заложения генеративных зачатков или же, при заложении, отстают и нестабильны в развитии. Среди соцветий побегов у растений S. jailensis in situ наиболее устойчивой структурой соцветия служит терминальный цветок на центральной оси побега. Генетически закрепленный тип соцветия - семицветковый двойной дихазий, in situ реализуется почти исключительно одно и двуцветковыми вариациями.

Причиной модификаций исходного соцветия служат факторы среды, которые лимитируют полноценное генеративное развитие растений in situ. Согласно проведенным наблюдениям, главным лимитирующим фактором для генезиса генеративных побегов и развития их соцветий выступает дефицит летнего тепла, который прямо отражается на качественно-количественных параметрах репродукции особей.

Генеративные зачатки у растений S. jailensis закладываются при среднесуточной температуре воздуха не менее $+15^{\circ} \mathrm{C}$, а цветение приурочено к среднесуточной температуре воздуха не менее $+18^{\circ} \mathrm{C}$. Эти термические параметры максимальны для яйлы и наблюдаются здесь весьма непродолжительный сезонный период.

По данным метеостанции «Ай-Петри» (1180 м над ур. м.), среднемноголетняя температура самого теплого месяца яйлы (июль) достигает $+15,1^{\circ} \mathrm{C}$. Период со средней суточной температурой более $+15^{\circ} \mathrm{C}$ в поясе выше 1000 м над ур. м. не превышает 40 58 дней. Отрицательные температуры на высотах 1000-1200 м над ур. м. перестают фиксироваться в июне и начинают фиксироваться в сентябре [КОчкин, 1967].

Погодные наблюдения в верховьях реки Авунда (высота около 1425 м н. у. м.) на Никитской яйле выявили здесь абсолютный максимум температуры воздуха в июленачале августа. Этот период отличают краткость и нестабильность погодных условий. «Минимальные суточные температуры отличаются низкими значениями. Возможно их падение до $0^{\circ} \mathrm{C}$ и ниже в любой летний месяц. Максимальные суточные температуры воздуха летом колеблются между +20 и $+30^{\circ} \mathrm{C}$. Резкие понижения температур, вплоть до заморозков, особенно характерны в июне. Они сопровождаются сильными ветрами, дождями с градом, холодными туманами. Особенно часты в июне отрицательные минимальные температуры, отмеченные почти во все декады за 4 года наблюдений. Эпизодически падения температур до отрицательных значений наблюдаются и в июле, а в последней декаде августа и в сентябре они опять становятся систематическими...» [ГОЛУБЕВ, 1978].

Обычные частые понижения температуры воздуха на яйле в начале и середине лета в период заложения генеративной сферы побегов приводят к формированию у растений S. jailensis одно-двуцветковых соцветий. В период цветения после первых ночных заморозков или при длительном понижении среднесуточной температуры воздуха ниже $+15^{\circ} \mathrm{C}$ все боковые структурные преобразования соцветий тормозятся и прекращаются: большая часть зачатков боковых осей и бутонов остаются недоразвитыми. При систематических ночных заморозках цветение и плодоношение растений прекращается.

Современные условия весенне-летнего периода климата яйлы слабо соответствуют потребностям генеративного развития растений S. jailensis. По этой причине вид сохранился лишь на отвесных скалах и бровках [РуБЦОВ, 1974; ЕНА, ЕНА, 2001, НикИФОРОВ, 2004]. Здесь растения получают больше тепла, чем на горизонтальных поверхностях. Тем не менее, и на скалах возможности генеративного развития растений ограничены. Время цветения растений S. jailensis в период термического оптимума на яйле совпадает с минимумом осадков. По этой причине вид локализован только в тех экотопах, в пределах которых летом в переходное время суток влага из воздуха конденсируется на быстро остывающих поверхностях и относительно медленно испаряется в дневное время [НикиФОРОВ, 2006]. 


\section{Выводы}

Исходное соцветие $S$. jailensis представляет собой семицветковый дихазий. Синфлоресценция реализуется в две стадии: фаза трехцветкового фрондофрондулозного цимоида и фаза фрондо-фрондулозно-брактеозного закрытого тирса.

У растений in situ абсолютно преобладают обедненные формы- варианты трехцветкового цимоида.

Лимитирующим фактором для семенного возобновления растений S. jailensis служит дефицит тепла при заложении генеративных зачатков и в начале цветения.

\section{Список литературы}

ГолУБЕВ В. Н. Эколого-биологические особенности растений и растительных сообществ Крымской яйлы // Тр. Гос. Никит. ботан. сада. - 1978. - Т. 74. - С. 5-70.

ЕнА Ан. В., ЕнА Ал. В. Генезис и динамика метапопуляции Silene jailensis N. I. Rubtzov (Caryophyllaceae) - реликтового эндемика флоры Крыма // Укр. ботан. журн. - 2001. - Т. 58, № 1. - С.27-34.

КондОРСКАЯ В. Р. О применении термина «дихазий» // Биологические науки. - 1989. - № 2. - С. 66-71.

КондоРскАя В. Р. О соцветиях Silenoideae // Бюл. МОИП. Отд. биол. - 1979. - Т. 84. - Вып. 5. - С. 78-92.

КузНЕцОВА Т. В. Методы исследования соцветий 1. Метод и концепция синфлоресценции Вильгельма Тролля // Бюл. МОИП. Отд. биол. - 1985. - Т. 90. - Вып. 3. - С. 67-89.

Кочкин М. А. Почвы, леса и климат Горного Крыма и пути их рационального использования. М. : Колос, 1967. $-368 \mathrm{c}$.

Никифоров А. Р. Популяция Silene jailensis N. I. Rubtzov (Caryophyllaceae) в составе экосистемы юговосточного прибровочного склона Никитской яйлы // Тр. Гос. Никит. ботан. сада. - 2004. T. 123 . - C. $29-35$.

НикифоРов А. Р. Местообитания и особенности цветения Silene jailensis N. I. Rubtzov (Caryophyllaceae) в составе популяции экосистемы юго-восточного прибровочного склона Никитской яйлы // Бюл. Гос. Никит. ботан. сада. - 2006. - Вып. 93. - С. 8-12.

НикИФоРов А. Р. Количественные параметры цветения Silene jailensis N. I. Rubtzov (Caryophyllaceae) в различных условиях // Бюл. Гос. Никит. ботан. сада. - 2007. - Вып. 95. - С. 5-8.

РуБцов Н. И. Новый вид p. Silene L. с Крымского нагорья (яйлы) // Бюл. Гос. Никитботан. сада. - 1974. Вып. 2 (24). - С. 5-8.

ФЕДОРОв Ал. А., АРтюшЕнко 3. Т. Атлас по описательной морфологии высших растений. Соцветие. Л.: Наука, 1979. -296 с.

Рекомендує до друку

Отримано 03.02.2009 p.

В.В. Корженевський

Aдрес автора:

А. Р. Никифоров

Никитский ботанический сад-

Национальный научный центр УААН

2. Ялта, АР Крылм, Украина, 98648

E-mail:nbs1812@ukr.net
Autor's addres:

A. R. Nikiforov

Nikita Botanical Garden-

National Scientific Center UAAS

Yalta, Crimea, Ukraine, 98648

E-mail:nbs1812@ukr.net 